\title{
Rezension: Recht mitgestalten. 150 Jahre Deutscher Juristentag. 1860 bis 2010
}

\author{
Deutscher Juristentag e.V. (djt) \\ Recht mitgestalten. 150 Jahre Deutscher Juristentag \\ 1860 bis 2010 \\ München 2010, C. H. Beck \\ 146 S., Klappenbroschur, 40,00 Euro \\ ISBN 978-3-406-60893-3
}

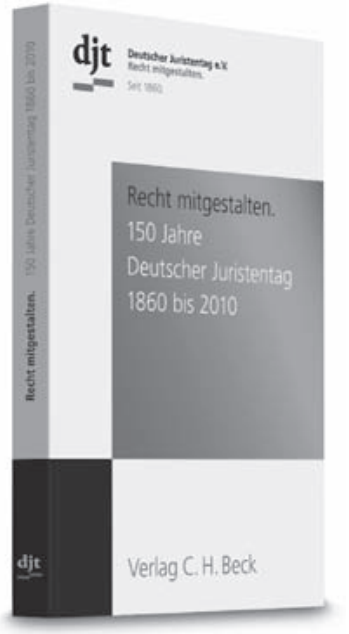

Vor 150 Jahren wurde der Deutsche Juristentag auf Initiative der Juristischen Gesellschaft zu Berlin gegründet. Knapp 150 Seiten hat die Jubiläumsschrift, in der das Geschichtsbüro Reder, Roeseling \& Prüfer aus Köln nun zu seinem Jubiläum die 150-jährige Geschichte des Deutschen Juristentags darstellt. Es wurden bewusst keine Jurist(inn)en sondern Historiker(innen) beauftragt, um „der Gefahr geschönter Selbstdarstellung zu entgehen “, so Henssler in seiner Begrüßungsrede am 22. September 2010. Das ist gelungen.

Die Zeitreise durch die Geschichte wird lebendig und kurzweilig erzählt.

Insbesondere ist den Autor(innen) hoch anzurechnen, dass sie die Juristinnen nicht vergessen haben. Dr. Marie Raschke, die erste Juristin, die Mitglied des djt wurde und eine der ersten deutschen Juristinnen überhaupt, wird genauso gewürdigt wie zahlreiche Juristinnen, die bei den Juristentagen der Zwanziger- und Dreißigerjahre wichtige Beiträge und Anregungen geliefert haben (siehe dazu ausführlich den Beitrag von Marion Röwekamp in diesem Heft, S. xxx). Nachdenklich stimmen die Kapitel über den Juristentag zur Zeit der NSDiktatur. Der 37. Deutsche Juristentag sollte 1933 in München stattfinden, wurde jedoch von der Deputation mit einer Gegenstimme abgesagt. Sieben der 24 Deputationsmitglieder waren jüdischer Herkunft, eines, Hugo Sinzheimer, war schon im März 1933 in „Schutzhaft“ genommen worden. Auf den Seiten 74 bis 83 ist nachzulesen, was aus ihnen und den anderen Deputationsmitglidern geworden ist. (AG)

\section{Juristinnen in der Geschichte des Deutschen Juristentags vor 1933}

\section{Dr. Marion Röwekamp}

John F. Kennedy Fellow, Center for European Studies, Harvard, Boston/USA

Nachdem der Deutsche Juristentag (djt) 1860 erstmals in Berlin stattgefunden hatte, nahm seine Bedeutung für die deutsche Rechtswissenschaft stetig zu. Er spiegelte er in der Regel die allgemeine Haltung der Juristen bei bestimmten Gesetzesvorhaben wider. ${ }^{1}$ Gesetzgeberische Bemühungen für Frauen waren in den ersten Jahrzehnten seines Bestehens selten Anliegen. Die Gleichberechtigung der Geschlechter in Ehe und Familie war im Kontext der Kodifizierung des neuen Bürgerlichen Gesetzbuchs 1888 in Stettin erstmals Thema des djt. Der Juristentag konnte sich mit den neuen, die Frauen im Familien- und Eherecht diskriminierenden Regelungen, die später in das BGB übernommen wurden, unproblematisch anfreunden. Die Interessen von Frauen wurden innerhalb der Geschichte des Deutschen Juristentages erst mit dem Auftreten der ersten Juristinnen wahrgenommen. Bereits deshalb lässt sich anhand ihrer Teilnahme auch in der Geschichte des djt eine Veränderung feststellen. ${ }^{2}$
1902 erschien erstmals auf einem Deutschen Juristentag „,auch ein weiblicher Jurist, Frl. Dr. Raschke aus Berlin “, die dem djt gleichzeitig auch beitrat. ${ }^{3}$ Marie Raschke hatte 1899 in Bern studiert und gehörte mit Anita Augspurg zu den ersten deutschen Juristinnen. Seit Mai 1896 war sie Vorsitzende der Berliner Zentralstelle für Rechtsschutz und der neugegründeten Rechtskommission des Bundes deutscher Frauenvereine (BDF). Auf dem 28. Innsbrucker Juristentag 1904 ergriff Raschke im Kontext der Strafrechtsreform im Hinblick auf die Behandlung minderjähriger Straftäter als erste Frau in der Geschichte des djt das Wort. Ihren Antrag, eine Stellungnahme zu dem Thema zu verschieben, da sich innerhalb der Frauenbewegung noch keine einheitliche Ansicht gebildet habe, fand

1 Herrman, Conrad u.a., Der Deutsche Juristentag 1860-1994, München 1997; Waldmann, Anke/Becker, Wibke, Der Deutsche Juristentag 1860-2010: 150 Jahre Deutscher Juristentag 1860-2010, München 2010.

2 So auch Ursula Rust, 100 Jahre Frauen in der Rechtswissenschaft Zur Beteiligung von Juristinnen am wissenschaftlichen Diskurs, in: Schöck-Quinteros, Eva/Dickmann, Elisabeth (Hg.), Barrieren und Karrieren. Die Anfänge des Frauenstudiums in Deutschland, 343362 (355).

3 Waldmann, Anke/Becker, Wibke, Der Deutsche Juristentag, $52 \mathrm{f}$. 